\title{
miR-1 suppresses the growth of esophageal squamous cell carcinoma in vivo and in vitro through the downregulation of MET, cyclin D1 and CDK4 expression
}

\author{
SEN JIANG $^{1,2^{*}}$, CHAO ZHAO $^{1,2^{*}}$, XIAODI YANG ${ }^{3}$, XIANGYANG LI $^{1,2}$, QING PAN $^{4}$, HAIJIN HUANG $^{1,2}$, \\ XUYANG WEN ${ }^{1,2}$, HUSHENG SHAN ${ }^{1,2}$, QIANWEN LI ${ }^{1,2}$, YUNXIANG DU ${ }^{1,2}$ and YAPING ZHAO ${ }^{1,2}$ \\ ${ }^{1}$ The 82 nd Hospital of the People's Liberation Army, Huaian, Jiangsu 223001; ${ }^{2}$ Department of Postgraduates, \\ BengBu Medical College, Bengbu, Anhui 233004; ${ }^{3}$ Department of Gastroenterology, Shanghai Sixth People's Hospital, \\ School of Medicine, Shanghai Jiaotong University, Shanghai 200030; ${ }^{4}$ Department of Laboratory Medicine, \\ Huaiyin Hospital of Huaian city, Huaian, Jiangsu 233004, P.R. China
}

Received March 14, 2015; Accepted May 10, 2016

DOI: $10.3892 /$ ijmm.2016.2619

\begin{abstract}
Several aberrant microRNAs (miRNAs or miRs) have been implicated in esophageal cancer (EC), which is widely prevalent in China. However, their role in EC tumorigenesis has not yet been fully elucidated. In the present study, we determined that miR-1 was downregulated in esophageal squamous cell carcinoma (ESCC) tissues compared with adjacent non-neoplastic tissues using RT-qPCR, and confirmed this using an ESCC cell line. Using a nude mouse xenograft model, we confirmed that the re-expression of miR-1 significantly inhibited ESCC tumor growth. A tetrazolium assay and a trypan blue exclusion assay revealed that miR-1 suppressed ESCC cell proliferation and increased apoptosis, whereas the silencing of miR-1 promoted cell proliferation and decreased apoptosis, suggesting that miR-1 is a novel tumor suppressor. To elucidate the molecular mechanisms of action of miR-1 in ESCC, we investigated putative targets using bioinformatics tools. MET, cyclin D1 and cyclin-dependent kinase 4 (CDK4), which are involved in the hepatocyte growth factor (HGF)/MET signaling pathway, were found to be targets of miR-1. miR-1 expression inversely correlated with MET, cyclin D1 and CDK4 expression in ESCC cells. miR-1 directly targeted MET, cyclin D1 and CDK4, suppressing ESCC cell growth. The newly identified miR-1/MET/cyclin D1/CDK4 axis provides new insight into
\end{abstract}

Correspondence to: Professor Yunxiang Du or Professor Yaping Zhao, The 82nd Hospital of the People's Liberation Army, 100 Jiankang Road, Huaian, Jiangsu 223001, P.R. China

E-mail: shojie308@163.com

E-mail: zyp82yy@aliyun.com

*Contributed equally

Abbreviations: miR-1, microRNA-1; EC, esophageal cancer; ESCC, esophageal squamous cell carcinoma; CDK4, cyclin-dependent kinase 4

Key words: microRNA, esophageal squamous cell carcinoma, microRNA-1, MET, cyclin D1, cyclin-dependent kinase 4 the molecular mechanisms of ESCC pathogenesis and indicates a novel strategy for the diagnosis and treatment of ESCC.

\section{Introduction}

Esophageal cancer (EC) is one of the most common types of cancer; it ranks eighth in terms of cancer incidence worldwide and is the sixth leading cause of cancer-related mortality worldwide (1). The two main types of EC are esophageal squamous cell carcinoma (ESCC) and esophageal adenocarcinoma (EA) (2). A unique feature of EC is its geographical distribution. An 'EC belt', primarily of ESCC, extends from North-Central China to the Middle East (3). Early-stage EC does not present with specific symptoms; the majority of patients present with advanced/metastatic disease at diagnosis (4) and the 5-year survival rate is $<20 \%$ for advanced tumors (5). However, the precise molecular mechanisms of its pathogenesis remain largely unknown. Thus, to improve clinical care and the early detection of EC, it is necessary to gain a deeper understanding of its molecular mechanisms and genetic networks.

Although an increasing amount of evidence indicates that EC has a multifactorial etiology which involves numerous environmental, genetic susceptibility and dietary factors, the molecular pathogenesis of these tumors is poorly understood (6). Tumor growth can be facilitated by genetic alterations in cancer cells that regulate the phenotypic changes. Genetic alterations play an important role in EC, and alterations in a large number of oncogenes and tumor suppressor genes have previously been described in patients with EC (7). Moreover, emerging evidence from the molecular characterization of microRNAs (miRNAs or miRs) suggests that miRNAs may act as tumor suppressors or oncogenes (8).

miRNAs belong to a class of conserved, endogenous, non-coding small RNAs that negatively regulate gene expression at the post-transcriptional level by mainly binding to the 3' untranslated regions (3'-UTRs) of mRNAs, resulting in mRNA degradation or the inhibition of translation (9). Many types of human disease, particularly cancer, have been linked to the deregulation of miRNA expression. Recent findings have shown 
that approximately $50 \%$ of human miRNAs are located in cancerassociated genomic regions or fragile sites and, depending on their targets, can function as tumor suppressor genes or oncogenes (10).

To date, several study groups have suggested that human endogenous miRNAs are associated with oncogenesis and tumor progression in EC. It was previously noted that the expression levels of 6 miRNAs (miR-21, miR-100, miR-99a, miR-203, miR-143 and miR-145) were significantly altered in patients with EC (11). miR-210 has been shown to suppress cell proliferation and regulate apoptosis in EC through the suppression of fibroblast growth factor receptor-like 1 (FGFRL1) (12). Moreover, human miRNAs such as miR-375, miR-129-2, miR-21, miR-143, miR-518b, miR-133 and miR-29c are aberrantly expressed in cancer, thus contributing to the development and progression of EC, as well as other types of cancer such as prostate cancer (13-19).

In a previous study, we used miRNA microarray analysis to generate specific expression profiles of miRNAs in ESCC cells, including miR-1 (20), whose expression levels were significantly altered in ESCC samples. However, the function of miR-1 in ESCC remains unknown. miR-1 is believed to act as a tumor suppressor and is known to be downregulated in human cancers $(21,22)$. However, the roles of miR-1 deregulation in carcinogenesis and cancer progression remain largely elusive. Hence, in the present study, we focused on miR-1 expression and its role in the development of ESCC. To the best of our knowledge, the role that miR-1 plays in EC has not previously been discussed. Therefore, in the present study we aimed to analyze miR-1 expression and to use in vitro and in vivo approaches in order to understand the functions and mechanisms of action of this miRNA in ESCC. We examined the level of miR-1 expression in human ESCC cells and tissues and investigated the potential role of miR-1 in ESCC tumorigenesis in a murine model. We also examined its effects on cell growth and apoptosis. Lastly, we explored the underlying mechanisms of miR-1 functions in ESCC. In silico analysis further revealed that the key oncogenes, MET, cyclin D1 (also known as $C C N D 1)$ and cyclin-dependent kinase $4(C D K 4)$, involved in the hepatocyte growth factor (HGF)/MET signaling pathway, were targets of miR-1. The direct inhibition of MET, cyclin D1 and CDK4 translation by miR-1, and its potential involvement as a suppressor of esophageal tumorigenesis, were validated experimentally. The present study thus provides us with a better understanding of ESCC pathogenesis.

\section{Materials and methods}

Clinical specimens. From 2009 to 2011, 34 pairs of primary ESCC tissues and the corresponding adjacent non-neoplastic esophageal tissues were obtained from the 82nd Hospital of the People's Liberation Army (Huaian, China). All tissue samples were obtained from untreated patients undergoing tumor resection and were either snap-frozen in liquid nitrogen for miRNA extraction, or fixed in $10 \%$ buffered formalin solution and then paraffin-embedded for histological analysis. Based on clinicopathological data, the samples were classified by age ( $\leq 60$ years, $n=18 ;>60$ years, $n=16)$, gender (male, $n=27$; female, $n=7$ ), grade of differentiation (well differentiated, $n=12$; moderately differentiated, $n=17$; poorly differentiated, $n=5$ ), degree of tumor invasion (submucosa, $\mathrm{n}=3$; muscularis propria, $\mathrm{n}=30$; adventitia, $\mathrm{n}=1$ ) and lymph node metastasis (negative, $\mathrm{n}=26$; positive, $\mathrm{n}=8$ ). Both tumor and normal tissues were histologically confirmed by hematoxylin and eosin (H\&E) staining. All participants provided written informed consent for the use of their samples for research, and the 82nd Hospital of the People's Liberation Army Ethics Committee approved the research protocols.

Cell culture. All cell lines [KYSE-150 (ESCC cells), Het-1A (normal esophageal cells), QBC939 (cholangiocarcinoma cells), HepG2 (hepatocellular carcinoma cells), AGS (gastric adenocarcinoma cells) and and human 293T cells were purchased from the American Type Culture Collection (ATCC; Manassas, VA, USA). The cells were cultured in RPMI-1640 medium (Gibco, Grand Island, NY, USA) supplemented with $10 \%$ (v/v) fetal bovine serum (FBS; Gibco) and incubated at $37^{\circ} \mathrm{C}$ in a humidified chamber containing $5 \% \mathrm{CO}_{2}$. When required, the media were supplemented with $2 \mu \mathrm{g} / \mathrm{ml}$ penicillin and $100 \mathrm{mg} /$ $\mathrm{ml}$ streptomycin (both from Invitrogen, Carlsbad, CA, USA).

$R N A$ isolation and reverse transcription-quantitative PCR $(R T-q P C R)$. Total RNA, including miRNA, was isolated from the cells (or tumor tissues) using a Qiagen miRNeasy kit (Qiagen GmbH, Hilden, Germany) according to the manufacturer's instructions. RNA was quantified at $260 \mathrm{~nm}$ using a spectrophotometer (Beckman Coulter, Inc., Brea, CA, USA) at an optical density $260 / 280 \mathrm{~nm}$ at a ratio of $1.8-2.0$ for all samples. Reverse transcription reactions were carried out using a TaqMan MicroRNA Reverse transcription kit (Applied Biosystems, Foster City, CA, USA) in a total reaction volume of $15 \mu \mathrm{l}$ for $30 \mathrm{~min}$ at $16^{\circ} \mathrm{C}, 30 \mathrm{~min}$ at $42^{\circ} \mathrm{C}$ and $5 \mathrm{~min}$ at $85^{\circ} \mathrm{C}$. Mature miRNA quantification was performed using TaqMan miRNA analysis for miR-1. The PCR conditions were as follows: $95^{\circ} \mathrm{C}$ for $10 \mathrm{~min}$, and then 40 cycles of $95^{\circ} \mathrm{C}$ for $15 \mathrm{sec}$ and $60^{\circ} \mathrm{C}$ for $1 \mathrm{~min}$. The qPCR results were analyzed and expressed as the relative miRNA expression of the threshold cycle value. The reverse transcription primers, $\mathrm{PCR}$ primers and TaqMan probe for miRNA were purchased from Applied Biosystems. U6 RNA was used as an internal control to normalize the miRNA. All qPCR assays were performed in triplicate in a 96-well plate using an ABI 7500 sequence detector system (Applied Biosystems) according to the manufacturer's instructions.

Tumorigenicity assay. To establish a xenograft tumor model, approximately $1 \times 10^{7} \mathrm{KYSE}-150$ cells were subcutaneously implanted in the right flanks of female BALB/c athymic nude mice (aged 4-5 weeks; Vital River Laboratory Animal Technology, Beijing, China). Tumor growth was examined every day for 21 days. Once the cancer cells had developed into palpable tumors, tumor volumes were calculated as follows: $\mathrm{V}=1 / 2 \times \mathrm{D} \times \mathrm{d}^{2}$, where $\mathrm{D}$ and $\mathrm{d}$ were the longest and shortest diameter of the tumor, respectively. When the tumors reached an average volume of $100 \mathrm{~mm}^{3}$, the mice were randomly divided into 4 groups ( $n=7$ per group) for a daily intratumoral injection of miR-1 mimics, miR-1 mimics-negative control (NC) or in vivo transfection agent (Entranster ${ }^{\mathrm{TM}}$-in vivo; Engreen, Inc., Beijing, China) or cisplatin (Qilu Pharmaceutical Co., Ltd., Jinan, China) as positive controls for 21 days, which has been used as a first-line therapy for patients with EC (23). For each injection, $5 \mu \mathrm{g} \mathrm{miR-1}$ mimics or miR-1 mimics-NC were mixed with $8 \mu 1$ transfec- 
tion reagent and diluted with phosphate-buffered saline (PBS) at $50 \mu \mathrm{g} / \mathrm{ml}$ to achieve the desired dose. Growth curves were plotted using the average tumor volume of each experimental group every day. Twenty-one days following implantation, the mice were sacrificed (mice anesthetetized with $0.3 \%$ pentobarbital sodium, followed by euthanasia after $1 \mathrm{~h}$ ) and the tumors were resected and weighed after necropsy, as previously described (24). All animal handling and experimental procedures were approved by the Animal Experimental Ethics Committee of Joinn Laboratories (Joinn Laboratories, Inc., Suzhou, China) (Permit number: ACU-12-094).

Cell transfection. The miR-1 gain-of-function experiments using KYSE-150 cells were performed using miR-1 mimics (100 nM) purchased from Shanghai GenePharma Co., Ltd., (Shanghai, China) and its negative control (NC, $100 \mathrm{nM})$. The loss-offunction experiments using KYSE-150 cells were performed using miR-1 inhibitor (100 nM) and its NC (100 nM). The miR-1 inhibitor was 2'-O-methyl oligoribonucleotides, purchased from GenePharma. For each experiment, we included a negative control. The cells were transfected using Lipofectamine ${ }^{\mathrm{TM}} 2000$ (Invitrogen) in Opti-MEM (Gibco) according to the manufacturer's instructions. The transfection efficiency was confirmed by the RT-qPCR detection of miR-1 expression.

Luciferase assay. The 3'-UTRs of MET, cyclin D1 and CDK4 containing the hsa-miR-1 binding site were amplified by PCR. This portion was cloned using the $X b a \mathrm{I}$ site in a pGL3 Control vector (Promega, Madison, WI, USA), downstream of the reporter gene. Control constructs and various 3'-UTR reporter constructs were co-transfected into $293 \mathrm{~T}$ cells. The cells were cultured in 24-well plates and transfected with $500 \mathrm{ng}$ of either 3'-UTR reporter constructs or pGL3 control vector together with $50 \mathrm{ng}$ of pRL-TK vector (Promega) and $100 \mathrm{nmol} / \mathrm{l}$ of miR-1, anti-miR-1 or negative controls. At $24 \mathrm{~h}$ following transfection, the luciferase activity was measured by Dual-Luciferase reporter assay (Promega). Each transfection was repeated twice in triplicate.

MTT assay. KYSE-150 cells $\left(5 \times 10^{3} /\right.$ well) were plated in 96-well plates in a final volume of $100 \mathrm{ml}$ and transfected with the miRNAs. Following transfection, the cells were cultured for $0,24,36,48,60$ and $72 \mathrm{~h}$. The effects of miR-1 on cell growth and viability were then determined. At the indicated time points, tetrazolium (MTT) reagent was added followed by incubation for $4 \mathrm{~h}$ at $37.5^{\circ} \mathrm{C}$. The supernatant was discarded and replaced with dimethyl sulfoxide to dissolve the formazan product. The absorbance was measured at $490 \mathrm{~nm}$ using a spectrophotometric plate reader (UV-200; Beckman Coulter, Inc.).

Trypan blue exclusion assay. The KYSE-150 cells (5x10³/well) were plated in 96-well plates in a final volume of $100 \mathrm{ml}$ and transfected with miR-1 mimics, inhibitors and their respective NCs. At 0, 24, 36 and 48 h following transfection, the cells were digested with parenzyme (Invitrogen GmbH, Darmstadt, Germany). The cells were counted using a hemocytometer; dead cells stained with trypan blue dye were counted to determine the number of viable cells.

Apoptosis assay. The rate of apoptosis was analyzed using an Annexin V-fluorescein isothiocyanate (FITC) Apoptosis detection kit (Beyotime Institute of Biotechnology, Shanghai, China). At $48 \mathrm{~h}$ following transfection, the cells were harvested and resuspended in binding buffer containing Annexin V-FITC and propidium iodide according to the manufacturer's instructions. The samples were analyzed using a flow cytometer (FACScan; BD Biosciences, San Jose, CA USA). The cells were categorized into viable, necrotic and apoptotic cells using BD FACSDiva 6.1.3 software (BD Biosciences), and the percentages of apoptotic cells from each group were compared. All experiments were repeated in triplicate.

Western blot analysis. The transfected cells were harvested for western blot analysis following $48 \mathrm{~h}$ of incubation. The cells were washed once in PBS and lysed in protein lysis buffer; protein concentrations were measured using a bicinchoninic acid (BCA) protein assay kit (Pierce, Rockford, IL, USA). Total protein was separated by sodium dodecyl sulfate-polyacrylamide gel electrophoresis using a $12 \%$ polyacrylamide gel and electroblotted onto a polyvinylidene fluoride membrane (Millipore, Billerica, MA, USA). The membrane was immunoblotted overnight at $4^{\circ} \mathrm{C}$ with the following primary antibodies: rabbit monoclonal anti-human MET (1:500; D1C2; Cell Signaling Technology, Danvers, MA, USA), mouse monoclonal anti-human CDK4 (1:500; DCS156; Cell Signaling Technology) and rabbit monoclonal anti-human cyclin D1 (1:500; 92G2; Cell Signaling Technology) antibodies. The membrane was incubated with a secondary antibody, horseradish peroxidase (HRP)-conjugated goat immunoglobulin G $(1: 1,000 ; 13 \mathrm{E} 5$; Beyotime Institute of Biotechnology), for $1 \mathrm{~h}$ after 3 washes with Tris-buffered saline containing Triton X-100. Signals were detected with electrochemiluminescence detection reagent (Beyotime Institute of Biotechnology). Images were captured on Kodak film and quantified by Quantity One software (Bio-Rad Laboratories, Hercules, CA, USA). Western blot analysis of glyceraldehyde3-phosphate dehydrogenase (GAPDH; 14C10) on the same membrane was used as a loading control. Densitometric analysis of protein bands was performed using Image Lab software (Bio-Rad Laboratories). All experiments were performed in triplicate.

Immunohistochemistry. The resected tumor tissues were fixed in $4 \%$ paraformaldehyde, embedded in paraffin, cut into 4-mm-thick sections, and mounted on polylysine-coated slides, which were then deparaffinized, rehydrated and microwave-heated in sodium citrate buffer $(10 \mathrm{mM}, \mathrm{pH}$ 6.0) for antigen retrieval. Bovine serum albumin was used for blocking. The slides were then incubated with MET, cyclin D1 and CDK4 antibodies (Cell Signaling Technology) overnight at $4^{\circ} \mathrm{C}$ at the optimal dilutions and subsequently incubated with an HRP-conjugated secondary antibody at room temperature for $1 \mathrm{~h}$. All slides were independently analyzed by two experienced pathologists blinded to the patient data. Diaminobenzidine was applied for color development; in cases with $\geq 30 \%$ positive tumor cells, a section was considered to exhibit positive expression.

Bioinformatics. miR-1 target prediction and analysis were performed with the algorithms from TargetScan (http://www. targetscan.org/), PicTar (http://pictar.mdc-berlin.de/), miRanda (http://www.microrna.org/) and DIANA LAB TarBase 5.0 (http://diana.imis.athena-innovation.gr/DianaTools/index.php). 

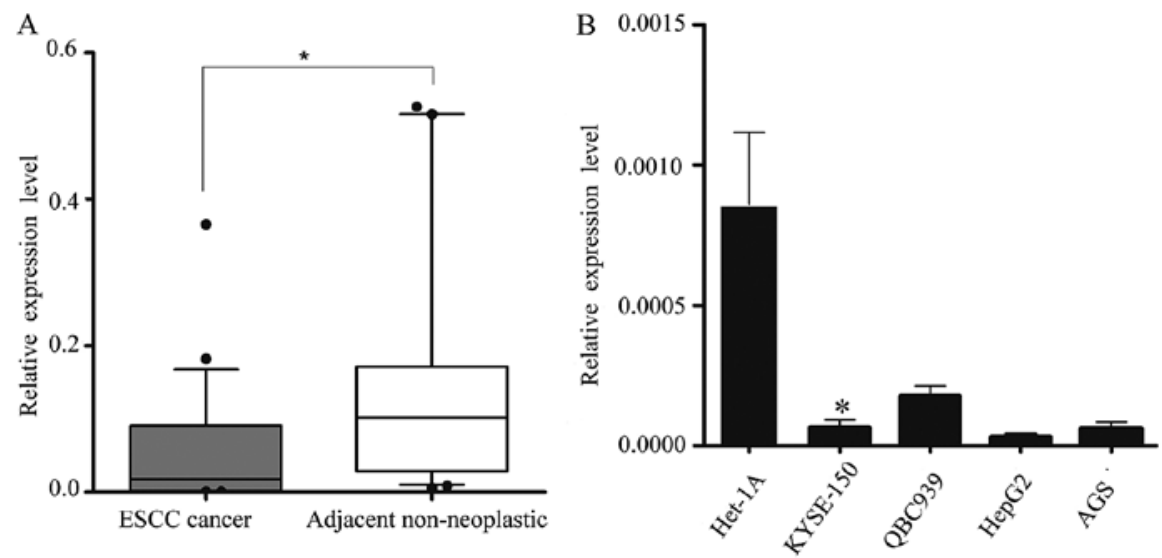

Figure 1. miR-1 expression in 34 paired esophageal squamous cell carcinoma (ESCC) tissues and other tumor cells. (A) miR-1 levels were determined in 34 surgical specimens of ESCC tissues and were normalized to those in corresponding adjacent non-neoplastic esophageal tissue specimens. "P<0.05. (B) RT-qPCR detection of miR-1 expression in Het-1A (normal esophageal), KYSE-150 (ESCC), QBC939 (cholangiocarcinomca), AGS (gastric adenocarcinoma) and HepG2 (hepaqtocellular carcinoma) cell lines. "P<0.05, KYSE-150 vs. Het-1A cells.

Statistical analysis. Unless otherwise stated, data are expressed as the means \pm standard error from at least 3 separate experiments performed in triplicate. All statistical analyses were performed using the t-test or Student-Newman-Keuls (SNK)-q test, and unless otherwise specified; the null hypothesis was rejected at the 0.05 level.

\section{Results}

miR-1 is downregulated in human ESCC tissues. We obtained 34 pairs of ESCC tissue samples and their corresponding adjacent non-neoplastic esophageal tissue specimens to examine the level of miR-1 expression using RT-qPCR. The average miR-1 expression level was significantly lower in the ESCC specimens than in the adjacent non-neoplastic tissue specimens, the relative expression level being $0.048 \pm 0.079$ vs. $0.182 \pm 0.280$ (Fig. 1A).

Subsequently, we isolated and compared miR-1 expression in malignant and non-malignant esophageal cells (KYSE-150 vs. Het-1A cells) (25), and confirmed the in vivo results. Consistent with the data obtained from the ESCC tumor tissues, miR-1 expression in malignant cells was markedly decreased when compared with the nonmalignant cells. miR-1 expression in other malignant cells, i.e., QBC939, AGS and HepG2 cells was also significantly decreased (Fig. 1B).

miR-1 suppresses the growth of ESCC xenograft tumors in nude mice. The KYSE-150 cells were injected subcutaneously into the right flanks of female nude mice. Tumors became palpable between 5 and 7 days after inoculation. All mice in the 4 groups (miR-1 mimics, miR-1 mimics-control, transfection agent and cisplatin) had developed tumors by the end of the experiment. Compared with the negative control groups (miR-1 mimics-control and transfection agent), the average tumor volume in the miR-1 mimics group was markedly decreased (Fig. 2A and C), as was the average tumor weight (Fig. 2B). Compared to the negative control groups, the average tumor volume and weight were also decreased in cisplatin positive control group.
miR-1 suppresses the growth of ESCC cells in vitro. It was thus proven that miR-1 is downregulated in ESCC, indicating its potential role in cell biological activities. We also confirmed that the miR-1 expression level was significantly increased by transfection with miR-1 mimics, using RT-qPCR (Fig. 3A). To characterize its functional importance in ESCC tumorigenesis, we further examined the effects of miR-1 on ESCC cell proliferation by MTT and trypan blue exclusion assays. miR-1 overexpression significantly inhibited cell proliferation at $48 \mathrm{~h}$, whereas the miR-1 inhibitor promoted proliferation at $24 \mathrm{~h}$ after transfection (Fig. $4 \mathrm{~A}$ and B). Consistent with the results of MTT assay, the results of trypan blue exclusion assay also demonstrated that miR-1 overexpression significantly inhibited ESCC cell viability (Fig. 4C and D).

miR-1 induces the apoptosis of ESCC cells. Apoptosis was measured by flow cytometry at $48 \mathrm{~h}$ following transfection with miR-1 or miR-1 inhibitor. The number of Annexin V-FITC(+) apoptotic cells was significantly increased in the miR-1 mimics-transfected group compared to the mimics-NCtransfected group. The percentage of apoptotic cells in the group treated with miR-1 inhibitor was higher than that of the inhibitor-NC group (Fig. 5).

miR 1 regulates $M E T$, cyclin $D 1$ and $C D K 4$ expression. To explore the mechanisms responsible for the growth inhibitory effects of miR-1, we used 4 miRNA target prediction programs, TargetScan (http://www.targetscan.org/), PicTar (http://pictar. mdc-berlin.de/), miRanda (http://www.microrna.org/) and DIANA LAB TarBase 5.0 (http://diana.imis.athena-innovation. gr/DianaTools/index.php), and identified 267 target genes regulated by miR-1 (data not shown).

Several genes reported to promote cell proliferation were selected for further analysis $(28,33,48,52)$. Among these, $M E T$, cyclin D1, and CDK4 were of particular interest, as they are involved in the cancer and HGF/MET pathways and are closely associated with cell proliferation. Therefore, we attempted to describe the mechanisms of action of miR-1 and its target genes, MET, cyclin Dl and CDK4, in ESCC. Using TargetScan and miRanda (Fig. 6A), we identified the putative 

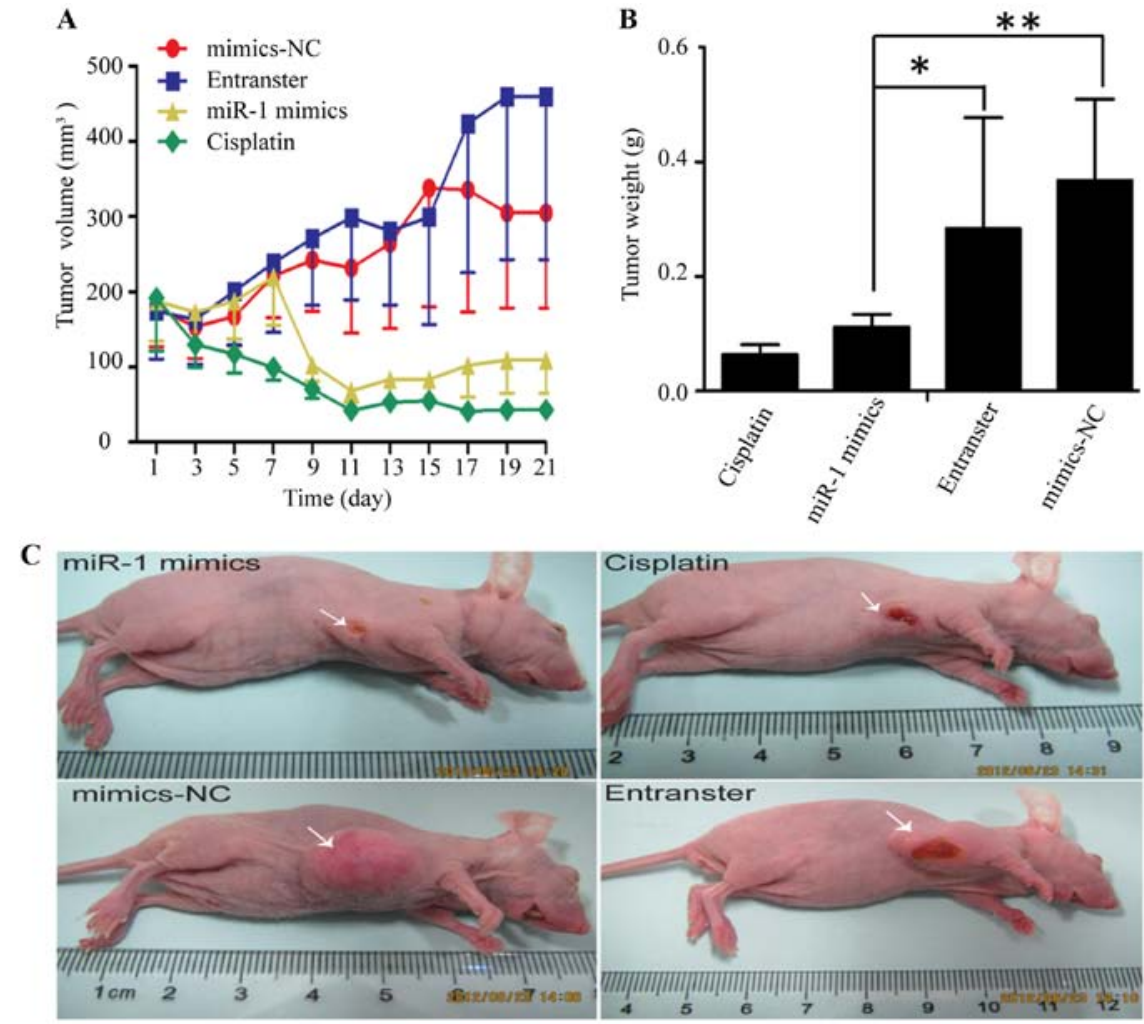

Figure 2. Effect of miR-1 overexpression on the growth of esophageal squamous cell carcinoma (ESCC) tumor xenografts. (A) Tumor growth curves after intratumor injection of miR-1 mimics, mimics negative control (mimics-NC), transfection reagent (Entranster) or cisplatin. (B) Tumor weights of the 4 experimental groups when the mice were sacrificed. (C) Mice carrying ESCC tumors following sacrifice on day $21 .{ }^{*} \mathrm{P}<0.05,{ }^{* *} \mathrm{P}<0.05$.
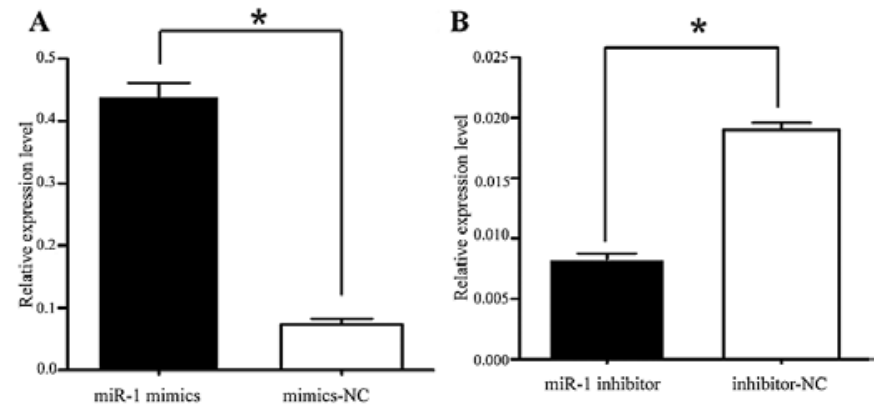

Figure 3. The expression of miR-1 in transfected KYSE-150 cells. (A) KYSE-150 cells were transiently transfected with miR-1 mimics (100 nM), (B) miR-1 inhibitor $(100 \mathrm{nM})$, or the respective negative controls. Transfection efficiency was determined by RT-qPCR. Data were normalized to U6 expression. Data are represented as the means \pm SEM from 3 independent experiments (" $\mathrm{P}<0.05)$.

binding sites for miR-1 in the 3'-UTR of MET, cyclin D1 and CDK4, which are highly conserved across species (Fig. 6B). We confirmed that the miR-1 expression level was significantly decreased following transfection with miR-1 inhibitor (Fig. 3B), confirming that the miR-1 inhibitor successfully regulated the miR-1 expression level in the KYSE-150 cells.To confirm that MET, cyclin D1 and CDK4 are downstream targets of miR-1, miR-1 mimics or inhibitor were transfected into the KYSE-150 cells. Compared to transfection with mimics-NC, transfection with miR-1 mimics significantly decreased MET, cyclin D1 and CDK4 protein expression (Fig. 6C). By contrast, the protein expression of MET, cyclin D1, and CDK4 was increased in the loss-of-function experiments following transection with
miR-1 inhibitor compared to transfection with miR-1 inhibitorNC (Fig. 6C).

Elevated expression of MET, cyclin D1 and CDK4 in human ESCC. To investigate whether MET, cyclin D1 and CDK4 are upregulated in ESCC, we detected their expression levels in ESCC tissues by immunohistochemical staining. We revealed that MET, cyclin D1 and CDK4 were commonly overexpressed in ESCC tissues compared with their paired adjacent non-neoplastic tissues (Fig. 7A). However, no association was observed between the miR-1 levels and MET, cyclin D1 and CDK4 staining in the 34 pairs of ESCC tissues (Fig. 7B).

miR-1 directly targets MET, cyclin D1 and CDK4. In order to determine whether miR-1 directly targets the 3'-UTR of MET, cyclin D1 and CDK4, a luciferase construct containing the 3'-UTR of MET, cyclin D1 and CDK4 was transfected with miR-1, anti-miR-1, or negative controls and then assayed by a luciferase reporter. MET, cyclin D1 and CDK4 exhibited a 1.2- to 2-fold decrease in luciferase activity when co-transfected with miR-1, and a significant 1- to 2-fold increase when co-transfected with anti-miR-1 when compared with the negative control (Fig. 8). Taken together, these findings indicate a direct interaction between miR-1 and MET, cyclin D1 and CDK4 mRNA.

\section{Discussion}

miRNAs are one of the most important discoveries in recent years in the field of molecular medicine. Calin et al (10) found that miRNAs were mostly localized to tumor-associated fragile 

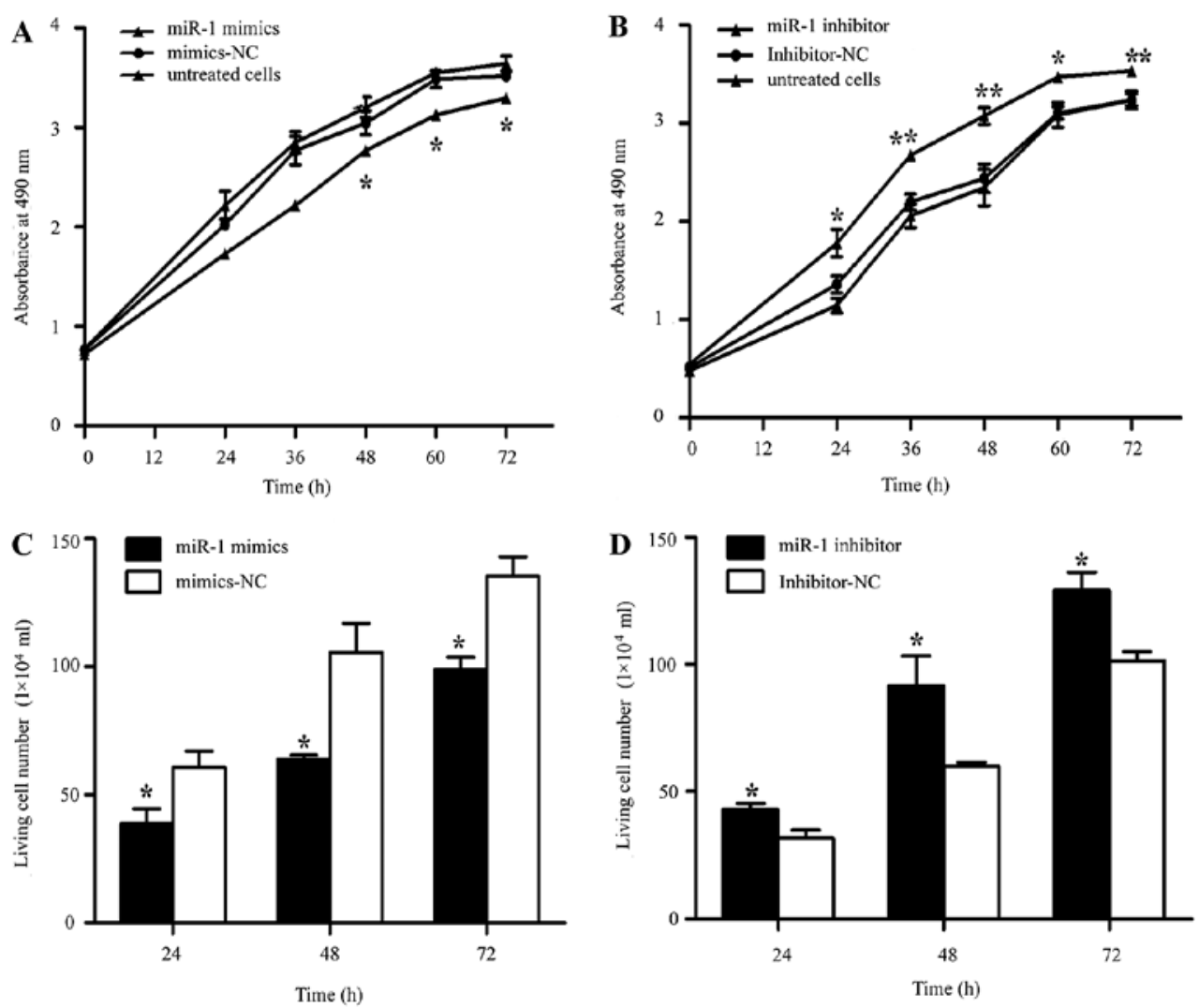

Figure 4. Effect of miR-1 overexpression/downregulation on cell proliferation. (A) MTT assay following transfection with miR-1 mimics or mimics-negative control (NC). ${ }^{~} \mathrm{P}<0.05$, miR-1 mimics vs. mimics-NC (B) MTT assay following transfection with miR-1 inhibitor and inhibitor-NC. ${ }^{*} \mathrm{P}<0.05$, miR-1 inhibitor vs. inhibitorNC. (C) Living cell counts following transfection with miR-1 mimics or mimics-NC. (D) Living cell counts following transfection with miR-1 inhibitor or inhibitor-NC. Data are represented as the means $\pm \mathrm{SEM} \pm \mathrm{SD}$. ${ }^{\mathrm{P}}<0.05,{ }^{* *} \mathrm{P}<0.01$.
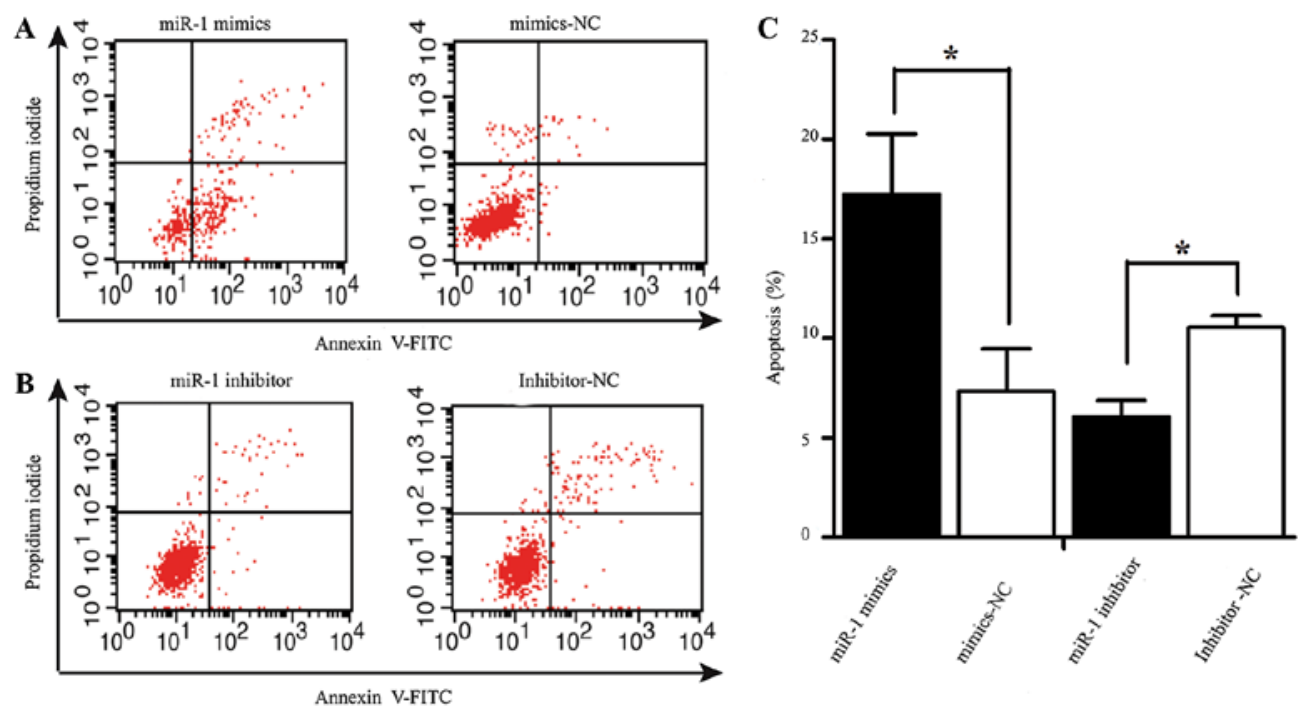

Figure 5. Effect of miR-1 overexpression/downregulation on apoptosis. (A and B) Flow cytometric analysis of apoptosis following transfection with miR-1 mimics, inhibitor and their respective NCs. (C) Rate of apoptosis was determined following transfection with miR-1 mimics, inhibitor and their respective NCs. ${ }^{*} \mathrm{P}<0.05$.

sites and are closely linked to the occurrence and development of tumors. There is evidence to indicate that miRNAs are involved in the pathogenesis of EC, and miRNA expression profiles can be used to distinguish different types of EC tissues. Studies have shown that miRNA expression in ESCC exhibits both organizational and geographical specificity. In Beijing,
China, Guo et al (26) identified 7 miRNAs that could be used to distinguish malignant $\mathrm{EC}$ lesions from adjacent normal tissues: miR-25, miR-424 and miR-151 expression in tumor tissues was significantly upregulated; that of miR-100, miR-99a, miR-29c and miR-140* was significantly decreased. Researchers have found that miRNA expression patterns differ between ESCC 
A

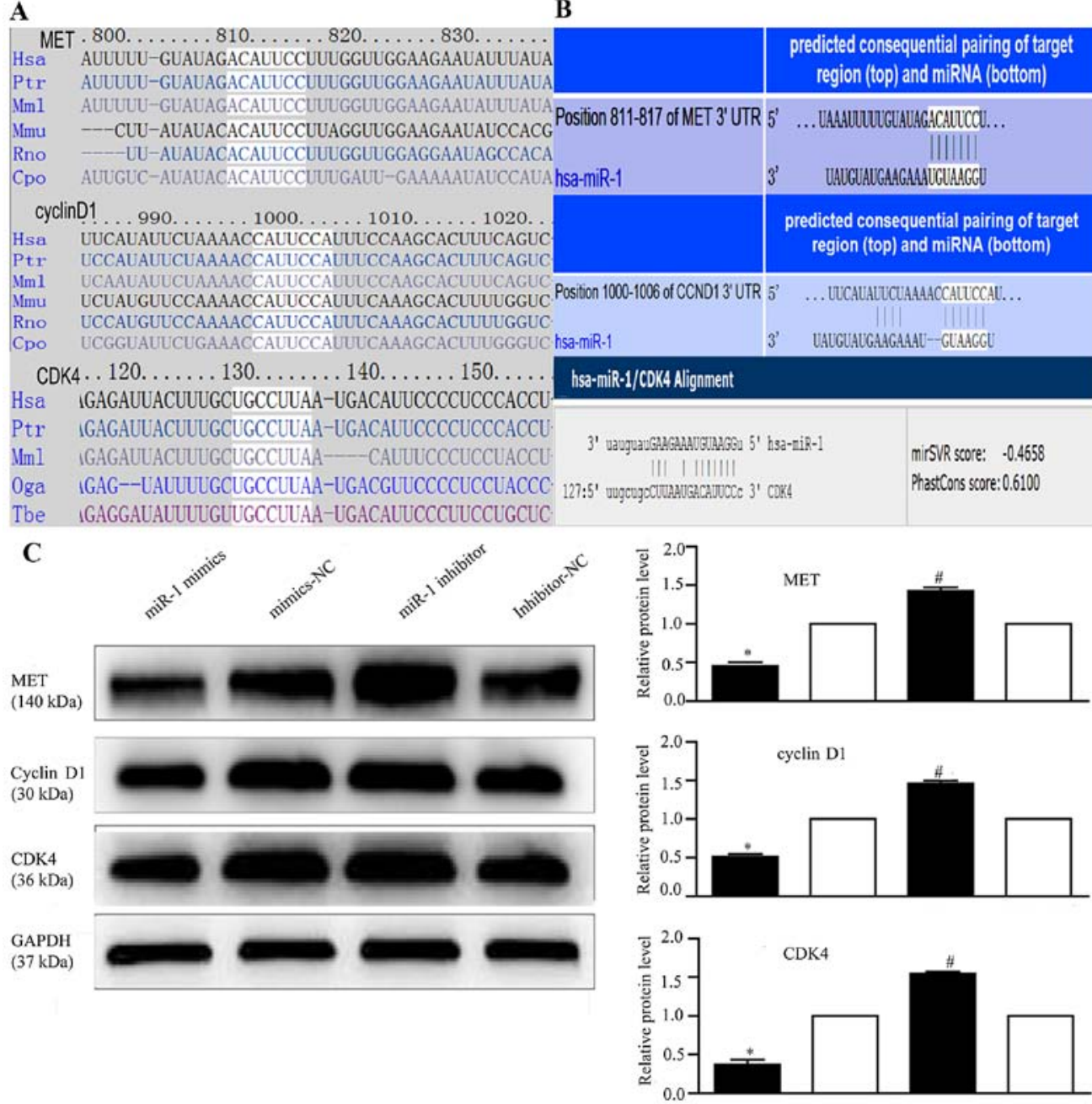

Figure 6. miR-1 targets 3'-UTR of MET, cyclin D1 and cyclin-dependent kinase 4 (CDK4). (A) Conservation of the predicted miR-1 binding site in MET/cyclin D1/CDK4 3'-UTR across species. (B) Bioinformatics analysis of the interaction between miR-1 and MET, cyclin D1 and CDK4 3'-UTR binding sites. (C) Effect of miR-1 overexpression/downregulation on MET, cyclin D1 and CDK4 expression by western blot analysis, with GAPDH as the internal control. Proteins were quantified by densitometric analysis, which was performed using Quantity One software (Bio-Rad Laboratories). ${ }^{*} \mathrm{P}<0.05$, ${ }^{*} \mathrm{P}<0.05$.

and EA; for example, in ESCC, miR-21 and miR-373 were overexpressed and miR-375 expression was low; in EA however, miR-21, miR-223, miR-192 and miR-194 were upregulated, and miR-203 and miR-31 were downregulated $(27,28)$. Japanese scholars have also reported that miR-150, miR-205, miR-218 and miR-203 are involved in the formation and progression of tumors in ESCC $(25,29-31)$. In the present study, we report on miR-1 expression in patients with ESCC from Huaian, China, which is a topic that has never previously been reported in ESCC or EA, to the best of our knowledge. Accordingly, we speculate that miR-1 may play a more important role in ESCC in the Huaian region in China.

A growing body of evidence indicates that miR-1 is involved in the growth and spread of multiple tumors, and that it functions as a tumor suppressor (32-34). Using an miRNA microarray, Japanese scholars (35) constructed miRNA expression profiles of head and neck squamous cell carcinomas (SCCs), and reported significantly low miR-1 expression. In the present study, we also noted the downregulated miR-1 expression in ESCC. miR-1 suppressed tumorigenesis in an ESCC xenograft murine model. In addition, we demonstrated that miR-1 was downregulated in QBC939, AGS and HepG2 cells. Thus, it is highly likely that miR-1 plays a fundamental role in EC tumorigenesis, and our findings are thus relevant to other tumors in which miR-1 is downregulated.

Under normal circumstances, cell proliferation and apoptosis are in equilibrium; however, the equilibrium is lost in malignant cells. Unrestricted proliferation and suppressed apoptosis are the root causes of tumor development. A number of studies have shown that miR-1 regulates cell proliferation, differentiation and apoptosis. Taulli et al (36) confirmed that miR-1 overexpression promotes the myogenic differentiation of rhabdomyosarcoma cells, while inhibiting cell proliferation. Wu et al (37) found that nasopharyngeal carcinoma cells transfected with miR-1 exhibited typical apoptotic metabolic processes, which were associated with low prothymosin alpha (PTMA) expression. In addition, Nohata et al $(38,39)$ found that miR-1 inhibited the proliferation and induced the apoptosis of maxillary sinus SCC cells by targeting transgelin 2 (TAGLN2) and purine nucleoside phosphorylase (PNP). Our preliminary study demonstrated that miR-1 was downregulated in ESCC tissues (20), but no data are available, as of yet, on its functions. The results of the present study demonstrate that miR-1 overexpression inhibits ESCC cell proliferation 

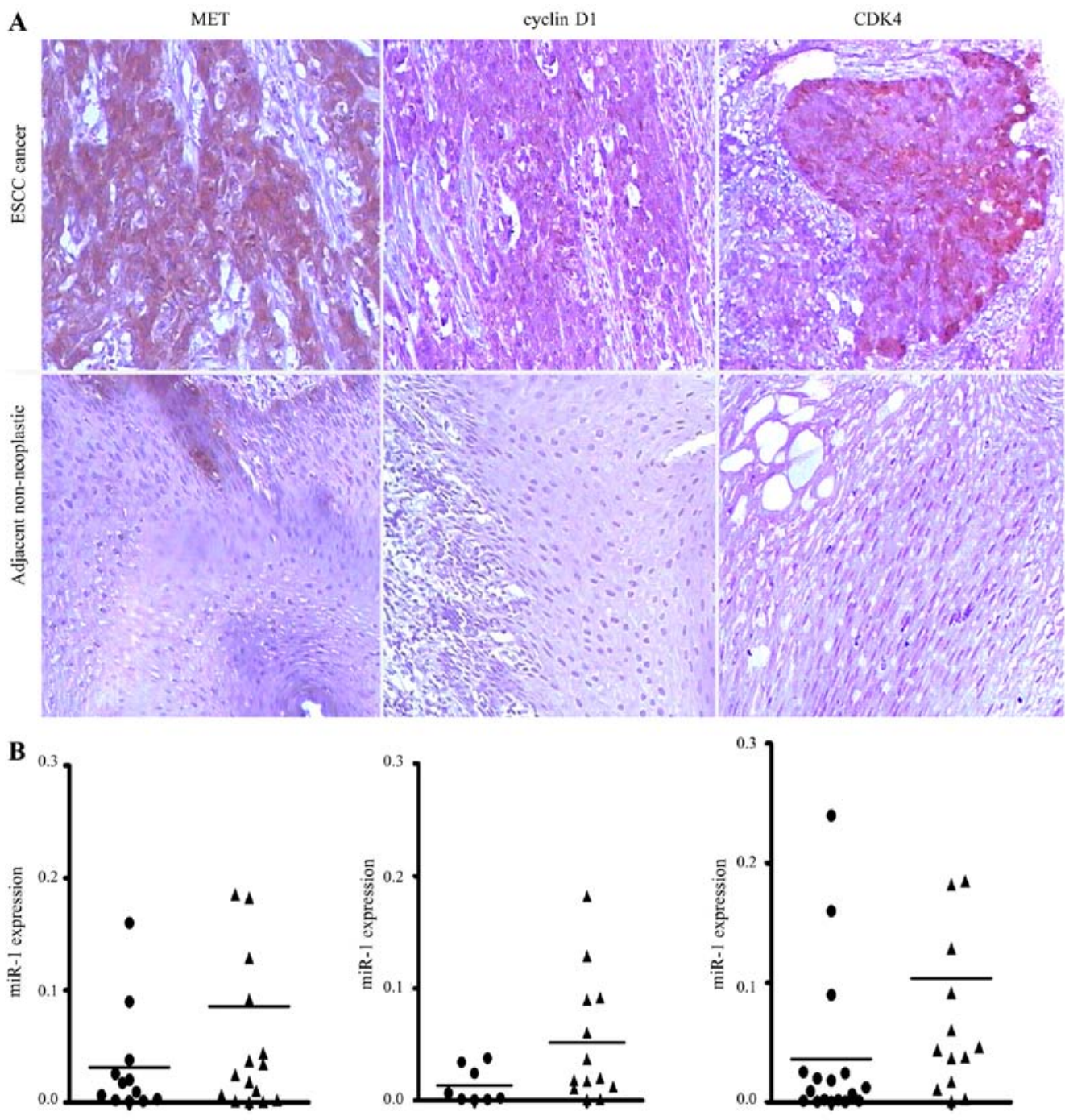

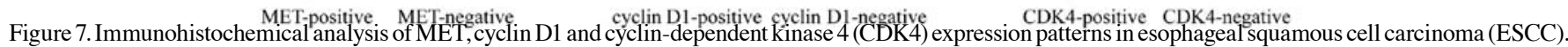
(A) Representative images of immunohistochemical staining for MET, cyclin D1 and CDK4 in human ESCC tissues and adjacent non-neoplastic tissues (original magnification, x100). (B) The expression levels of MET, cyclin D1 and CDK4 in ESCC tissues did not directly correlate with the miR-1 expression levels.
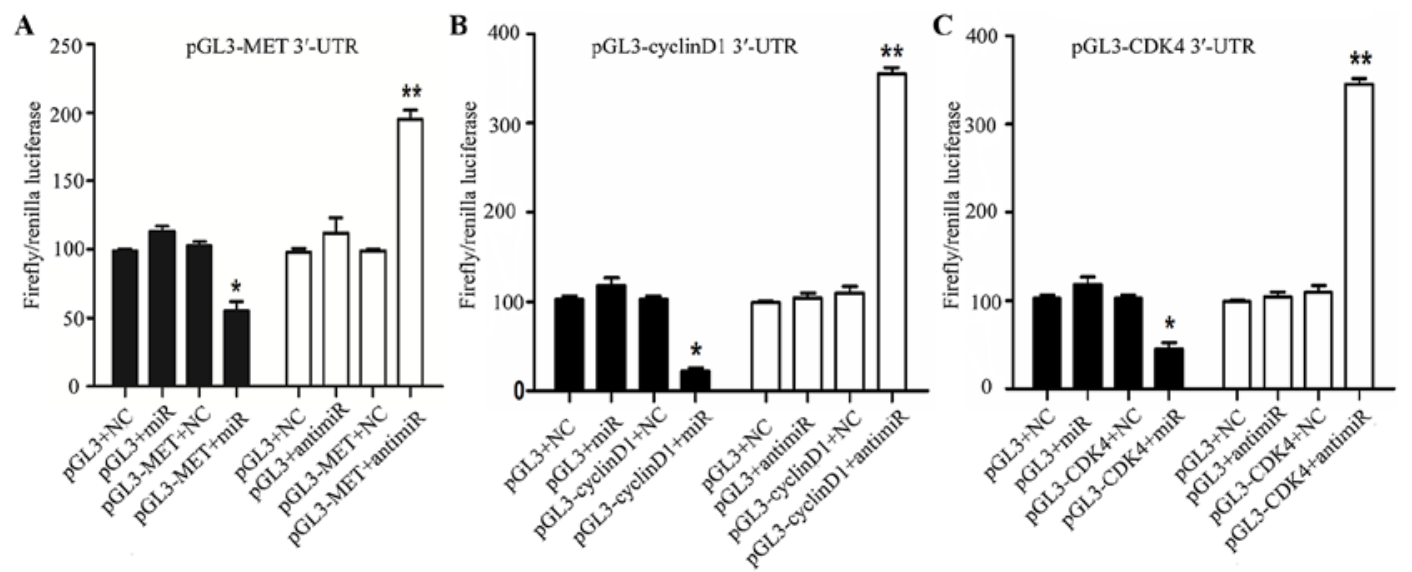

Figure 8. Luciferase activity assay with MET, cyclin D1 and CDK4 3'-UTR construct co-transfected into 293T cells. Schematic representation of luciferase activity assay of MET, cyclin D1 and CDK4 3'-UTR construct or control luciferase construct co-transfected with miR-1, anti-miR-1 or negative controls. ${ }^{*} \mathrm{P}<0.05,{ }^{* *} \mathrm{P}<0.01$.

and promotes apoptosis, whereas miR-1 silencing promotes cell proliferation and inhibits apoptosis, suggesting that miR-1 may influence the formation and progression of ESCC by regulating cell proliferation and apoptosis. miR-518 can also inhibit ESCC cell proliferation (17); yet miR-1 plays a similar role in liver cancer, prostate cancer and other gastrointestinal tumors $(22,33,39,40)$. Therefore, miR-1 may be a potential target for ESCC treatment in the future. 
Abnormal miRNA expression has been reported in many types of cancer, and much attention has been focused on understanding the roles of miRNAs in modulating the process of cancer development, in which miRNAs exert their biological function by regulating their target genes $(24,25,40,41)$. Some target genes for miR-1 have been reported. Using genome-wide expression analysis and luciferase reporter experiments, Kojima et al (40) confirmed that miR-1 directly regulated the significantly increased expression of the PNP gene in prostate cancer tissues. It is well known that the average miRNA has approximately 100 target sites (41). However, the same gene may also simultaneously be subject to a number of specific precise temporal miRNA regulations; consequently, the roles of miRNAs in cancer are very complex. In the present study, to explore the molecular mechanisms responsible for the growth inhibitory effects of miR-1, we first used bioinformatics analysis tools to predict miR-1 target genes. Further analysis determined that 3 target genes (MET, cyclin Dl and CDK4) were involved in the HGF/MET signaling pathway, which is closely associated with cell proliferation. Western blot analysis confirmed that miR-1 significantly affected the expression of the 3 target proteins, suggesting that it directly regulates the 3 target genes. However, in the tissues, no statistical correlation was found through immunohistochemistry, perhaps too few cases were included.

There is an increasing amount of evidence demonstrating that, in ESCC cell lines and tissues, the expression of multiple molecular targets of the HGF/MET signaling pathway, e.g., MET, cyclin D1 and CDK4, is abnormal (42-44). The HGF/MET signaling pathway plays an important role in regulating cell proliferation and apoptosis, and it is closely associated with a variety of tumors (45-49). The HGF/MET signaling pathway exerts its effects by activating the single receptor MET, which then binds to a number of intracellular target proteins, triggering downstream cascades involved in the regulation of a variety of biological activities, such as cell proliferation and apoptosis $(42,50,51)$. MET is the encoding oncogene for the HGF receptor (HGFR). A key protein in the HGF/MET signaling pathway involved with tyrosine kinase activity, MET affects cell proliferation, apoptosis, invasion, migration and angiogenesis via interactions with critical molecules of the Wnt and phosphatidylinositol-3-kinase (PI3K) signaling pathways. MET expression is abnormal in ESCC and EA, cancer of the stomach, pancreas, liver and colon, as well as in other tumors (45-49). miR-1 plays a tumor suppressor role by directly regulating MET expression in colon cancer, rhabdomyosarcoma and osteosarcoma $(21,52,53)$. Our results suggest that in ESCC, miR-1 also inhibits tumor growth through the direct regulation of MET.

Cyclin D1 and CDK4 are located downstream of MET in the HGF/MET signaling pathway. Recent studies have shown that the expression of cyclin D1 and CDK4 is abnormal in a variety of tumors, including EC, and affects tumorigenesis and tumor development $(54,55)$. Cyclin D1 overexpression enables the continuous proliferation of cancer cells, leading to tumorigenesis (54). CDK4 can bind with cyclin D1 to form complexes, affecting cell cycle regulation and cell proliferation (55). Given the results of the present study, that miR-1 directly regulates MET, cyclin D1 and CDK4, we hypothesized that miR-1 regulates cell proliferation in two ways: i) by regulating MET expression, thereby affecting the expression of the downstream molecules cyclin D1 and CDK4; and ii) by targeting cyclin D1 and CDK4 directly. We posit that
MET, cyclin D1 and CDK4 of the HGF/MET signaling pathway form a regulatory network around miR-1, which is then involved in the regulation of ESCC development.

Taken together, our results suggest that miR-1 is a tumor suppressor miRNA in human ESCC, which acts through the repression of MET, cyclin D1 and CDK4 expression. Our data provide further evidence of the pivotal role that miRNAs play in ESCC tumorigenesis. As miR-1 is downregulated in ESCC, the re-introduction of this mature miRNA into the tumor tissue may be a therapeutic strategy that reduces the expression of target genes. Although miRNA-based therapeutics are still in their infancy, our findings are encouraging and suggest that miR-1 may be a potential target for future ESCC treatment.

\section{Acknowledgements}

The authors would like to thank Dr Conglin Zuo for his kind provision of Joinn Laboratories (Suzhou, China) and his advice for our experiments. The present study was supported by the Jiangsu Natural Science Foundation (BK2012666).

\section{References}

1. Ferlay J, Shin HR, Bray F, Forman D, Mathers C and Parkin DM: Estimates of worldwide burden of cancer in 2008: GLOBOCAN 2008. Int J Cancer 127: 2893-2917, 2010.

2. Vizcaino AP, Moreno V, Lambert R and Parkin DM: Time trends incidence of both major histologic types of esophageal carcinomas in selected countries, 1973-1995. Int J Cancer 99: 860-868, 2002.

3. Jemal A, Bray F, Center MM, Ferlay J, Ward E and Forman D: Global cancer statistics. CA Cancer J Clin 61: 69-90, 2011.

4. Layke JC and Lopez PP: Esophageal cancer: a review and update. Am Fam Physician 73: 2187-2194, 2006.

5. Stoner GD and Wang LS: Chemoprevention of esophageal squamous cell carcinoma with berries. Top Curr Chem 329: 1-20, 2013.

6. Kamangar F, Chow WH, Abnet CC and Dawsey SM: Environmental causes of esophageal cancer. Gastroenterol Clin North Am 38: 27-57, 2009.

7. Hyland PL, Freedman ND, Hu N, Tang ZZ, Wang L, Wang C, Ding T, Fan JH, Qiao YL, Golozar A, et al: Genetic variants in sex hormone metabolic pathway genes and risk of esophageal squamous cell carcinoma. Carcinogenesis 34: 1062-1068, 2013.

8. Calin GA and Croce CM: MicroRNA signatures in human cancers. Nat Rev Cancer 6: 857-866, 2006.

9. Bartel DP: MicroRNAs: genomics, biogenesis, mechanism, and function. Cell 116: 281-297, 2004.

10. Calin GA, Sevignani C, Dumitru CD, Hyslop T, Noch E, Yendamuri S, Shimizu M, Rattan S, Bullrich F, Negrini M, et al: Human microRNA genes are frequently located at fragile sites and genomic regions involved in cancers. Proc Natl Acad Sci USA 101: 2999-3004, 2004

11. Wu BL, Xu LY, Du ZP, Liao LD, Zhang HF, Huang Q, Fang GQ and Li EM: MiRNA profile in esophageal squamous cell carcinoma: downregulation of miR-143 and miR-145. World J Gastroenterol 17: 79-88, 2011.

12. Tsuchiya S, Fujiwara T, Sato F, Shimada Y, Tanaka E, Sakai Y, Shimizu K and Tsujimoto G: MicroRNA-210 regulates cancer cell proliferation through targeting fibroblast growth factor receptor-like 1 (FGFRL1). J Biol Chem 286: 420-428, 2011.

13. Kong KL, Kwong DL, Chan TH, Law SY, Chen L, Li Y, Qin YR and Guan XY: MicroRNA-375 inhibits tumour growth and metastasis in oesophageal squamous cell carcinoma through repressing insulin-like growth factor 1 receptor. Gut 61: 33-42, 2012.

14. Kang M, Li Y, Liu W, Wang R, Tang A, Hao H, Liu Z and Ou H: miR-129-2 suppresses proliferation and migration of esophageal carcinoma cells through downregulation of SOX 4 expression. Int J Mol Med 32: 51-58, 2013.

15. Wang N, Zhang CQ, He JH, Duan XF, Wang YY, Ji X, Zang WQ, Li M, Ma YY, Wang T and Zhao GQ: MiR-21 down-regulation suppresses cell growth, invasion and induces cell apoptosis by targeting FASL, TIMP3, and RECK genes in esophageal carcinoma. Dig Dis Sci 58: 1863-1870, 2013. 
16. Ni Y, Meng L, Wang L, Dong W, Shen H, Wang G, Liu Q and Du J: MicroRNA-143 functions as a tumor suppressor in human esophageal squamous cell carcinoma. Gene 517: 197-204, 2013.

17. Zhang M, Zhou S, Zhang L, Zhang J, Cai H, Zhu J, Huang $\mathrm{C}$ and Wang J: miR-518b is down-regulated, and involved in cell proliferation and invasion by targeting Raplb in esophageal squamous cell carcinoma. FEBS Lett 586: 3508-3521, 2012.

18. Tao J, Wu D, Xu B, Qian W, Li P, Lu Q, Yin C and Zhang W: microRNA-133 inhibits cell proliferation, migration and invasion in prostate cancer cells by targeting the epidermal growth factor receptor. Oncol Rep 27: 1967-1975,2012.

19. Ding DP, Chen ZL, Zhao XH, Wang JW, Sun J, Wang Z, Tan FW, Tan XG, Li BZ, Zhou F, et al: miR-29c induces cell cycle arrest in esophageal squamous cell carcinoma by modulating cyclin $\mathrm{E}$ expression. Carcinogenesis 32: 1025-1032, 2011.

20. Fu HL, Wu P, Wang XF, Wang JG, Jiao F, Song LL, Xie H, Wen XY, Shan HS, Du YX and Zhao YP: Altered miRNA expression is associated with differentiation, invasion, and metastasis of esophageal squamous cell carcinoma (ESCC) in patients from Huaian, China. Cell Biochem Biophys 67: 657-668, 2013.

21. Novello C, Pazzaglia L, Cingolani C, Conti A, Quattrini I, Manara MC, Tognon M, Picci P and Benassi MS: miRNA expression profile in human osteosarcoma: role of miR-1 and miR-133b in proliferation and cell cycle control. Int J Oncol 42: 667-675, 2013.

22. Nohata N, Hanazawa T, Enokida $H$ and Seki N: microRNA-1/133a and microRNA-206/133b clusters: dysregulation and functional roles in human cancers. Oncotarget 3: 9-21, 2012.

23. Hou G, Zhang Q, Wang L, Liu M, Wang J and Xue L: mTOR inhibitor rapamycin alone or combined with cisplatin inhibits growth of esophageal squamous cell carcinoma in nude mice. Cancer Lett 290: 248-254, 2010.

24. Wang F, Zhang P, Ma Y, Yang J, Moyer MP, Shi C, Peng J and Qin H: NIRF is frequently upregulated in colorectal cancer and its oncogenicity can be suppressed by let-7a microRNA. Cancer Lett 314: 223-231, 2012.

25. Matsushima K, Isomoto $H$, Yamaguchi $N$, Inoue $N$, Machida $H$ Nakayama T, Hayashi T, Kunizaki M, Hidaka S, Nagayasu T, et al: MiRNA-205 modulates cellular invasion and migration via regulating zinc finger E-box binding homeobox 2 expression in esophageal squamous cell carcinoma cells. J Transl Med 9: 30, 2011.

26. Guo Y, Chen Z, Zhang L, Zhou F, Shi S, Feng X, Li B, Meng X, Ma X, Luo M, et al: Distinctive microRNA profiles relating to patient survival in esophageal squamous cell carcinoma. Cance Res 68: 26-33, 2008.

27. Leidner RS, Ravi L, Leahy P, Chen Y, Bednarchik B, Streppel M, Canto M, Wang JS, Maitra A, Willis J, et al: The microRNAs, MiR-31 and MiR-375, as candidate markers in Barrett's esophageal carcinogenesis. Genes Chromosomes Cancer 51: 473-479, 2012.

28. Lee KH, Goan YG, Hsiao M, Lee CH, Jian SH, Lin JT, Chen YL and Lu PJ: MicroRNA-373 (miR-373) post-transcriptionally regulates large tumor suppressor, homolog 2 (LATS2) and stimulates proliferation in human esophageal cancer. Exp Cell Res 315: 2529-2538, 2009.

29. Yokobori T, Suzuki S, Tanaka N, Inose T, Sohda M, Sano A, Sakai M, Nakajima M, Miyazaki T, Kato H and Kuwano H: MiR-150 is associated with poor prognosis in esophageal squamous cell carcinoma via targeting the EMT inducer ZEB1. Cancer Sci 104: 48-54, 2013.

30. Takeshita N, Mori M, Kano M, Hoshino I, Akutsu Y, Hanari N, Yoneyama Y, Ikeda N, Isozaki Y, Maruyama T, et al: miR-203 inhibits the migration and invasion of esophageal squamous cell carcinoma by regulating LASP1. Int J Oncol 41: 1653-1661, 2012.

31. Yamamoto N, Kinoshita T, Nohata N, Itesako T, Yoshino H, Enokida H, Nakagawa M, Shozu M and Seki N: Tumor suppressive microRNA-218 inhibits cancer cell migration and invasion by targeting focal adhesion pathways in cervical squamous cell carcinoma. Int J Oncol 42: 1523-1532, 2013.

32. Leone V, D'Angelo D, Rubio I, de Freitas PM, Federico A Colamaio M, Pallante P, Medeiros-Neto G and Fusco A: MiR-1 is a tumor suppressor in thyroid carcinogenesis targeting CCND2, CXCR4, and SDF-1alpha. J Clin Endocrinol Metab 96: E1388-E1398, 2011

33. Li D, Yang P, Li H, Cheng P, Zhang L, Wei D, Su X, Peng J Gao H, Tan Y, et al: MicroRNA-1 inhibits proliferation of hepatocarcinoma cells by targeting endothelin-1. Life Sci 91 440-447, 2012.

34. Liu YN, Yin JJ, Abou-Kheir W, Hynes PG, Casey OM, Fang L, Yi M, Stephens RM, Seng V, Sheppard-Tillman H, et al: MiR-1 and miR-200 inhibit EMT via Slug-dependent and tumorigenesis via Slug-independent mechanisms. Oncogene 32: 296-306, 2013.
35. Nohata N, Sone Y, Hanazawa T, Fuse M, Kikkawa N, Yoshino H, Chiyomaru T, Kawakami K, Enokida H, Nakagawa M, et al: miR-1 as a tumor suppressive microRNA targeting TAGLN2 in head and neck squamous cell carcinoma. Oncotarget 2: 29-42, 2011.

36. Taulli R, Bersani F, Foglizzo V, Linari A, Vigna E, Ladanyi M, Tuschl T and Ponzetto C: The muscle-specific microRNA miR-206 blocks human rhabdomyosarcoma growth in xenotransplanted mice by promoting myogenic differentiation. J Clin Invest 119: 2366-2378, 2009.

37. Wu CD, Kuo YS, Wu HC and Lin CT: MicroRNA-1 induces apoptosis by targeting prothymosin alpha in nasopharyngeal carcinoma cells. J Biomed Sci 18: 80, 2011.

38. Nohata N, Hanazawa T, Kikkawa N, Sakurai D, Fujimura L, Chiyomaru T, Kawakami K, Yoshino H, Enokida H, Nakagawa M, et al: Tumour suppressive microRNA-874 regulates novel cancer networks in maxillary sinus squamous cell carcinoma. Br J Cancer 105: 833-841, 2011.

39. Nohata N, Hanazawa T, Kikkawa N, Sakurai D, Sasaki K, Chiyomaru T, Kawakami K, Yoshino H, Enokida H, Nakagawa M, et al: Identification of novel molecular targets regulated by tumor suppressive $\mathrm{miR}-1 / \mathrm{miR}-133 \mathrm{a}$ in maxillary sinus squamous cell carcinoma. Int J Oncol 39: 1099-1107, 2011.

40. Kojima S, Chiyomaru T, Kawakami K, Yoshino H, Enokida H, Nohata N, Fuse M, Ichikawa T, Naya Y, Nakagawa M and Seki N: Tumour suppressors miR-1 and miR-133a target the oncogenic function of purine nucleoside phosphorylase (PNP) in prostate cancer. Br J Cancer 106: 405-413, 2012.

41. Brennecke J, Stark A, Russell RB and Cohen SM: Principles of microRNA-target recognition. PLoS Biol 3: e85, 2005.

42. Kato H, Arao T, Matsumoto K, Fujita Y, Kimura H, Hayashi H, Nishiki K, Iwama M, Shiraishi O, Yasuda A, et al: Gene amplification of EGFR, HER2, FGFR2 and MET in esophageal squamous cell carcinoma. Int J Oncol 42: 1151-1158, 2013.

43. Grugan KD, Miller CG, Yao Y, Michaylira CZ, Ohashi S, Klein-Szanto AJ, Diehl JA, Herlyn M, Han M, Nakagawa H and Rustgi AK: Fibroblast-secreted hepatocyte growth factor plays a functional role in esophageal squamous cell carcinoma invasion. Proc Natl Acad Sci USA 107: 11026-11031, 2010.

44. Leelawat K, Leelawat S, Tepaksorn P, Rattanasinganchan P, Leungchaweng A, Tohtong R and Sobhon P: Involvement of c-Met/hepatocyte growth factor pathway in cholangiocarcinoma cell invasion and its therapeutic inhibition with small interfering RNA specific for c-Met. J Surg Res 136: 78-84, 2006.

45. Ketterer K, Kong B, Frank D, Giese NA, Bauer A, Hoheisel J, Korc M, Kleeff J, Michalski CW and Friess H: Neuromedin U is overexpressed in pancreatic cancer and increases invasiveness via the hepatocyte growth factor c-Met pathway. Cancer Lett 277: 72-81, 2009.

46. Zeng ZS, Weiser MR, Kuntz E, Chen CT, Khan SA, Forslund A, Nash GM, Gimbel M, Yamaguchi Y, Culliford AT IV, et al: c-Met gene amplification is associated with advanced stage colorectal cancer and liver metastases. Cancer Lett 265: 258-269, 2008

47. Ke AW, Shi GM, Zhou J, Wu FZ, Ding ZB, Hu MY, Xu Y, Song ZJ, Wang ZJ, Wu JC, et al: Role of overexpression of CD151 and/or c-Met in predicting prognosis of hepatocellular carcinoma. Hepatology 49: 491-503, 2009.

48. Drebber U, Baldus SE, Nolden B, Grass G, Bollschweiler E, Dienes HP, Hölscher AH and Mönig SP: The overexpression of c-met as a prognostic indicator for gastric carcinoma compared to p53 and p21 nuclear accumulation. Oncol Rep 19: 1477-1483, 2008.

49. Tuynman JBLS, Lagarde SM, Ten Kate FJ, Richel DJ and van Lanschot JJ: Met expression is an independent prognostic risk factor in patients with oesophageal adenocarcinoma. Br J Cancer 98: 1102-1108, 2008.

50. Cecchi F, Rabe DC and Bottaro DP: Targeting the HGF/Met signaling pathway in cancer therapy. Expert Opin Ther Targets 16: 553-572,2012.

51. Peters $S$ and Adjei AA: MET: A promising anticancer therapeutic target. Nat Rev Clin Oncol 9: 314-326, 2012.

52. Reid JF, Sokolova V, Zoni E, Lampis A, Pizzamiglio S, Bertan C, Zanutto S, Perrone F, Camerini T, Gallino G, et al: miRNA profiling in colorectal cancer highlights miR-1 involvement in MET-dependent proliferation. Mol Cancer Res 10: 504-515, 2012.

53. Yan D, Dong XE, Chen X, Wang L, Lu C, Wang J, Qu J and Tu L: MicroRNA-1/206 targets c-Met and inhibits rhabdomyosarcoma development. J Biol Chem 284: 29596-29604, 2009.

54. Shirali S, Aghaei M, Shabani M, Fathi M, Sohrabi M and Moeinifard M: Adenosine induces cell cycle arrest and apoptosis via cyclinD1/Cdk4 and $\mathrm{Bcl}-2 / \mathrm{Bax}$ pathways in human ovarian cancer cell line OVCAR-3. Tumour Biol 34: 1085-1095, 2013.

55. Fong LY, Nguyen VT, Farber JL, Huebner K and Magee PN: Early deregulation of the the p16ink4a-cyclin D1/cyclin-dependent kinase 4-retinoblastoma pathway in cell proliferation-driven esophageal tumorigenesis in zinc-deficient rats. Cancer Res 60: $4589-4595,2000$ 